\title{
Digital Technology to Support the Trade Union Movement
}

\author{
Klaus Schoemann \\ Jacobs University Bremen, Bremen, Germany \\ Email: k.schoemann@jacobs-university.de
}

How to cite this paper: Schoemann, K. (2018) Digital Technology to Support the Trade Union Movement. Open Journal of Social Sciences, 6, 67-82.

https://doi.org/10.4236/jss.2018.61005

Received: December 12, 2017

Accepted: January 15, 2018

Published: January 18, 2018

Copyright (C) 2018 by author and Scientific Research Publishing Inc. This work is licensed under the Creative Commons Attribution International License (CC BY 4.0).

http://creativecommons.org/licenses/by/4.0/

\begin{abstract}
New digital technologies have a potential to bypass traditional forms of labour organization. We summarize the academic and trade union literature on the potential of new digital technologies for trade unions. Building on the literature of the social construction of technology and democracy at work we present the concept of the technology-supported construction of the social sphere. A review of digital technologies allows us to identify the potential innovator role of trade unions and work councils in digital forms of employee participation. Digital technologies are an important way to attract younger generations of trade union members. For experienced members, bridging the digital divide becomes a vital issue, too. Finally, we highlight the active interplay and mutually reinforcing effect of online and offline communication in networking.
\end{abstract}

\section{Keywords}

Digital Technology, Employee Participation, Democracy at Work, Digital Divide, Liquid Democracy, Data Protection

\section{Introduction}

In this paper, we focus on the potentials that digital technologies offer to trade unions and works councils. Digital technologies range from hardware devices like smartphones and internet connected computers to networking software like social media, conference calling or elaborated voting systems. Many non-governmental organizations demonstrate already how to make use of digital technologies to organize movements and to stay in touch with members and the broader public by pro-active use of digital strategies. In view of declining trade union membership in the private sector in the U.S., albeit near stable membership in the public sector and an aging union membership challenge [1], 
making use of new digital technologies should be high on the agenda. Some trade unions have embraced new technologies to their advantage, like the movement against the contested French labour law reform [2]. Choosing and adopting specific carefully selected and tested applications and software, which suit union purposes, becomes an issue of strategic importance. Examples of digital technologies consist in new forms to better organize protests, improve decision-making or additional ways of keeping in touch with a more diverse membership. Shorter reaction times and more inclusive decision-making through digital technologies constitute an additional advantage.

In the early ages of digital technology, many people were afraid that printed forms of communication would soon disappear. Today we know that both forms of content provision co-exist. The same holds true for the use of digital technologies in organizing and supporting labour movements. Online and offline forms of organizing, voting and campaigning largely co-exist. As digital innovations found their way into our workplaces, homes, pockets and mind-sets [3], we want to stress the chances that prevail in actively shaping the adaptation of new technologies. Digital technologies play the role of a facilitator, but not a goal in itself [4].

Increasing democracy at work [5] or ensuring citizenship at work [6] are such ambitious goals. Some of the new digital technologies we present in this paper have already demonstrated their potential to support these ambitious goals in a very specific manner. New digital technologies should contribute in a precisely defined, potentially even measurable form, to the overriding goal to support organizations and members of the union movement. Despite the potential to weaken collective action and industrial relations ([3], p. 51), several items speak in favor of embracing digital technologies like possibilities for more autonomous work, new forms of collaboration and more "agile" organizations.

Efforts to improve democracy at work in operational terms on the shop floor can mean to make use of electronic forms of voting in order to allow for broader participation of workers who might be on leave, work part-time or do not devote a lot of time to deal with registering to vote or information handling. Digital applications that try to improve exactly those procedures are of importance in this area. Union representatives just as much as politicians in more direct forms of political participation can make use of advances in new digital technologies [7]. We present a short overview of the relevant literature in this field and shall discuss the potential to apply those concepts of new technologies' usefulness for the trade union movement. The role of new technologies for unions is evident in community organizing [8] or the supporting potential of digital technologies in organizing highly mobile transnational workers, for example in the construction sector [9].

Ever since the introduction of the concept of the digital divide [10], it is obvious that we have to guard against the risk of deepening rather than bridging the digital divide with the use of continuously advancing new digital technolo- 
gies. Pushing too early or too fast can also alienate union members, but most digital technologies we discuss in this paper have reached a considerable amount of maturity. Nevertheless, we need to weigh the pro and cons of technological advances of interest to unions. Additionally, unions have a crucial role to play in training provision to empower members to apply digital technologies to their advantage.

\section{Mechanisms of Employee Participation and Agenda Setting}

The issue of employee representation has received ample coverage in the whole industrial relations as well as human resource management literature. We take a short cut on this literature by looking at recent future-oriented contributions to the field [11]. With emphasis on the sustainable company, the contributions in this reader share the perspective to develop current modes of participation and governance. The chapter by Gospel ([12], p. 70) states in a nuanced way "that worker representation in decision-making does not hinder efficiency, but instead probably enhances it". Building on this statement, we propose to make use of modern information and communication technologies to a fuller extent to strengthen the participation of employees in form of voicing matters and preparation or participation in decision-making. The paper follows Gospel ([12], p. 59) in taking a "big brush" which means we use the terms worker or employee representation and participation interchangeably. We combine concepts of employee voice, involvement, engagement, empowerment as forms of industrial democracy or citizenship at work as variations of the same underlying theme.

\subsection{Varieties of Employee Participation}

Following the broad range of definitions of worker participation as succinctly exposed by Gospel [12] we shall summarize and combine some of the mechanism in order to expose more clearly the potential contribution of new digital technologies to these mechanisms. In analogy to the differentiation of direct and indirect democracy, there exist direct and indirect forms of employee representation. Employees participate directly or through a designated or elected representative, i.e. indirectly. Participation may also be exclusive for union members only or inclusive on behalf of all employees. Crossing these two dimensions yields a two by two table (Figure 1) which reflects the scope of a broad view of employee participation.

Inside Figure 1, the number of employees involved in the day-to-day decision-making is shown. It ranges from few persons in case of indirect, exclusive participation to many more for both categories of direct, but exclusive as well as inclusive, but indirect. The pure form of inclusive and direct would involve all persons eligible as in Swiss-type direct democracies with abundant and regular participation in form of a referendum for each topic. In practical terms, the latter form does not reach all persons eligible either, but at least in principle the de- 
cision-making process is open to all.

The arrows in Figure 1 indicate the feasible enlargement of participation in our view i.e. from involvement of few to many. The jump from involvement of few towards involvement of all has been tricky in most instances known to us so far. Probably a careful assessment of such democratic efforts to involve all seems extraordinarily hard to sustain over a longer period of time. The step from the few to many entails the need to increase professionalism, use of digital technologies, efficiency and knowledge management aspects of the participation process and experiences. Additionally, the form of co-existence of involving all and work councils changing roles is then in need of a re-balancing or complete re-definition. The same applies to the role of management and flat hierarchical decision structures in companies. Arrows indicate a feasible standard evolution, the diagonal dashed arrow indicates an ideal-type evolution which is inclusive of all employees as well as the elected representatives of unions.

Alternatively, as outlined in the definition part of the chapter by Gospel on the sustainable company ([12], p. 61) employee representation reflects steps on a ladder, albeit in our opinion the analogy to steps on a staircase with the many instances where an individual worker is represented by fellow worker for a specific case appears a more appropriate image. The second step consists of the entitlement of employee representatives on information and consultation, which involves fewer instances than the broad basis of peer to peer advice. Highest on the staircase figure the negotiations of works councils or trade unions representing members (Figure 2).

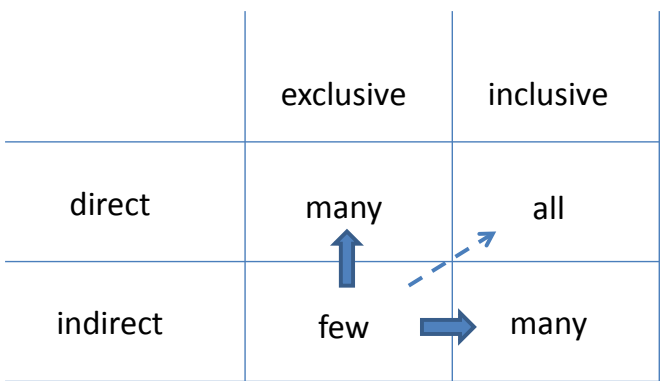

Figure 1. Number of employees involved by type of representation.

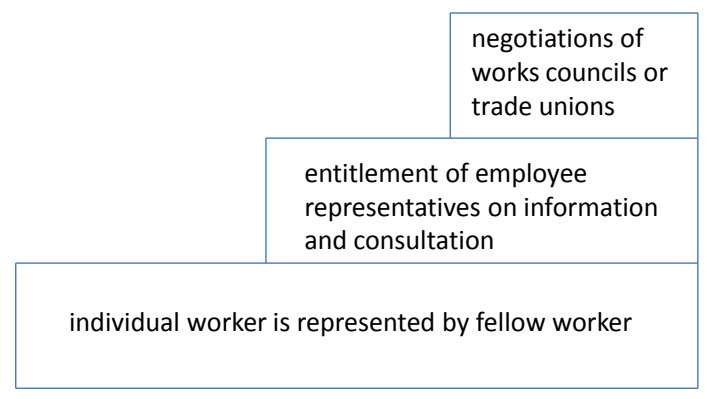

Based on (Gospel, 2011: 61), own representation

Figure 2. Hierarchical model of employees representation. 
In this realm of models, mechanisms or "requisite varieties" of worker representation we need to mention the more hierarchical forms, which distinguish levels like information of workers by management, consultation, negotiation, joint decision-making and ultimately board level representation. For the impact of information technologies and social media as part of this, the distinction into (1) task issues (wages, health and safety, employment protection) and (2) policy issues (strategic matters of influencing) is helpful. The set of new digital technologies supporting one form or the other is not identical. This view becomes even more obvious in the distinction into events-driven (for example the event of an announced plant closure) versus process-driven forms of representation ([12], p. 61). The organizational elements of the process-driven form may be easily supported by scheduling and document management software if data protection can be organized in a sufficiently secured way. Finally, the juxtaposition of de facto versus de jure systems reflects the different concerns about legal restrictions that apply to the persons who have permissions to represent and/or negotiate and the specific rules applying to this form. The de jure forms are well defined despite massive bodies of judicial literature, which itself have found their own new forms of electronic or digital registers of legislation and judgments of several instances of courts. Access management to such collections to members within the union movement might already be a route worth pursuing. Knowledge about rights "instantaneously" enables pro-active behavior.

\subsection{Digital Agenda Setting}

Not only the European Commission adopted a digital agenda recently [13], but also most Member States have intensified their efforts to advance the use of digital technologies in many fields of application. A systematic review and a list of initiatives are presented by Degryse [3]. Therefore, we concentrate on the relevance for trade unions themselves in this paper. Originally, most studies referring to digital technology focused mainly on the further development of the digital technology itself. Only recently, we witness a reified interest in studies on consequences of the use of digital technology for businesses, employees and consumers. Particularly the new wave of artificial intelligence applications with research projects and tests like emotion recognition by robots through voice or facial expression interpretation are hotly debated topics in the press and other media, but also among social scientists, lawyers, politicians, trade unionists, civil society representatives and engineers.

It is probably about time for unions also to embark on their own digital agenda. According to the dominant type of employee participation presented above such an agenda setting ideally follows principles of good practice strategic policy making. First, there are the substantive topics, for example providing a secured digital server for members or supporting access to "unionbook" (http://www.usunions.com/) a facebook version for unionists. Second, deadlines by when a certain technical infrastructure should be reached. Third, quantifiable 
targets of for example reaching out to new younger generations have to be identified. Fourth, monitoring and an evaluation of the progress is a constituent part of such an endeavor. Without such detailed agenda setting digital strategies of unions may remain ad hoc responses or partial strategies only.

On the European level and under the label "reinforcing trust and security in digital services" ([13], pp. 12-13) the Directive 2002/58/EC on e-privacy is already cited as inefficient since it applies only to telecom companies and not to other information society service providers. The idealistic policy objective of an inclusive e-society, which comprises digital skills, access and e-government, remains a steep challenge. The digital divide is at least twofold. On the one hand, within a country there are groups of society as well as regions that are disadvantaged; on the other hand there is a substantial gap between European countries for internet use and access [14]. These challenges were recently reiterated by various reports from think tanks (e.g. Arbeiterkammer, [15], p. 31; [16]).

Throughout the development of digital technologies, which we define as the combination of information and communication technologies, the notion of the digital divide accompanied the progress in the field. Originally, the digital divide [10] described the structural differences between users and non-users of digital technologies. However, by now there are several new dimensions added to this divide and they comprise for example a difference between rural and urban areas in terms of simple technical access, but also the different competence levels with which users make use of internet technology in problem-solving [17]. The so-called PISA for adults test of literacy and numeracy skills revealed astonishing numbers of persons with only basic skills in all OECD countries. From a trade union perspective, we should add the importance to consider the digital divide between employees in multi-national enterprises, other large firms compared to the many employees in small or medium size enterprises.

Digital technology can give a helping hand in collecting and releasing sensitive information on fraud or illegal non-legitimate behavior [Lux leaks, wikileaks or tax evasion) but also be part of spying activities (NSA) not only of secret services. For social scientists dealing with the digital technology spread we witness the well-known fact that new technology as such is considered neutral rather than have positive or negative effects. It is the different kind of use such new technology is put to, which determines positive outcomes in terms of gaining degrees of freedom in human action or restricting freedom [4]. Among the good practice of agenda setting in the union domain is the document of the Arbeiterkammer [15] from Vienna on digital change, albeit the detailed agenda setting still awaits focusing and concrete steps for implementation.

\section{Improving Mobilization and Accountability through Digital Technologies}

The second, more theory driven, motivation for this paper stems from the concern of how to ensure good democratic practices in voting systems and likely 
consequences of voting behavior. Fox and Shotts [18] have outlined a theory of political accountability, which highlights the differences between the voting for delegates or trustees. In the American constitutional debates this refers back to James Madison [19] who had raised these concerns in the drafting of the American constitution. The schism revealed in the Brexit vote lately, whereby elected politicians would have favored to stay in the EU, but the majority of voters decided in the direct democracy form of a referendum the opposite way, reflect the tension between voting as installing a trustee versus voting as designation of a delegate.

For local elections in England [20] the evidence shows that there is no reward for a candidate if the candidate shows an above average performance. Simple majority voting every four years does not seem to encourage outstanding performance. Even in the process of legislative activities, the entrusted political representative might decide to delegate the preparation of legislation to bureaucrats. The analysis by Fox and Shotts [18] shows that for voters it is more beneficial if legislators have only restricted possibilities to delegate preparation of legislation to bureaucrats or experts.

These developments and concerns about voting systems are taken up in the evolution of the so-called liquid democracy or liquid feedback debate. It is a kind of a positive answer to the "voter and delegate" paradox of potential alienation. Why is this important for unions? Richard Hyman ([5], p. 21) put it this way: "Unions cannot credibly campaign for the democratization of the economy unless they themselves are patently democratic". The vision statement of T3R1 the French union support for digital campaigning (https://syndicoop.fr/) and their efforts in the "Loi Travail" mobilization in France are a good showcase of the digital potential.

From a non-union case study [21] we learned that even in sensitive cases when employee voice under the European Information and Consultation Directive should apply, the concerned non-unionized employees used the modern information and communication channels through the internet for their needs. All persons involved in the action were in their mid-twenties. Besides the phone calls, the use of email was a major channel of communication. This probably reflects a cohort effect of the millennials generation rather than an age effect. The common way of communicating in this generation of digital natives is through the online communication irrespective of potential data protection risks.

The case study shows to some extent the potential to overcome the "digital divide" [10] as in the case study of a firm in the manufacturing industry of a multinational employer with production plants in several countries it is mostly blue collar workers that are concerned. Here we assume that enterprises, as in most production plants, do not provide internet access to employees in manufacturing or production line jobs while on duty. In fact, some firms make considerable efforts to suppress access even to make private phone calls from mobile phones. An employee's own internet access is likely to be available in such instances and 
sufficient trust in exclusive information sharing between activists seems to be present. Younger generations, also of blue-collar workers, reveal a different habit of communication and communication skills just like their peers of their own generation of "digital natives". This appears to be substantially different from previous generations.

Additionally, gender differences in form of labour market attachment controlled for factors of firm characteristics have an impact on union quitting behavior. A lack of flexible work arrangements seems to impede women not only to continue careers but also to give up on involvement to change the rules of the game through union involvement [22]. Kirton [23] offers a similar and even more nuanced conclusion for the difficulties encountered for women to participate in union activities in Great Britain. The work environment with confrontational industrial relations put additional stress on activists and the competence to enable a satisfactory work-life balance becomes crucial. The additional constraint of "chronic" time scarcity has limited women professionals' union participation. New communication technologies with their time saving and time flexibility potential can provide operational support. Emails can be answered or initiated at suitable times respecting work-life balances and scarcity of time for example of the many women who are caring simultaneously for children or relatives.

Brogger ([24], pp. 491-492) made a concrete statement on social dialogue in the evolving retail sector. In the past the sector was dominated by well-defined hierarchies with also a stable structure of positions within the hierarchies. This organizational structure determined arenas of contest as well as procedures for employees to participate and voice concerns. In modern organizational structures of conglomerates consisting of smaller units with considerable degrees of autonomy bottom-up approaches to employees' participation is needed in addition to the more traditional top-down ones. This was the conclusion of the research claiming transferability from the retail sector to the whole service sector of the industrial relations system.

More critical of the potential to use social media to organize strike actions are Upchurch and Grassman [25]. In their study of 2010-2011 British Airways cabin crew industrial action, the authors demonstrate that social media can assist in shaping the discourse and in mobilization of a greater amount of people. The additional communication channel might constitute a threat to the traditional internal union structure and attributed authorities. In addition, even a counter-mobilization occurred and the boundaries between the private life and work-related relationships become more blurred. Hence, the authors stress the complementary rather than substitution role of social media. In their words "Social media and collective text messaging oiled the machine of union mobilization, rather than built the machine" ([25], p. 30).

The recent application to establishment data of the exit-voice concept [26] shows that the introduction of a works council is the more likely the higher the 
firm-specific human capital is, at least in Germany. This might be due to the long-lasting high-wage, high skill strategy pursued in Germany, where market entry is more difficult for firms with low-skill, low-wage profile from a point of view of other European countries' wage levels in some sectors. High firm-specific human capital is most likely correlated with new forms of organizing of employees by help of digital technologies.

\section{Fostering Engagement-The Potential of Liquid Democracy within Firms and Unions}

The recommendations by Whittington and Galpin [27] of how to foster stronger commitment to organizations in a world apparently moving towards lower levels of commitment focus on trust in leaders as one of the key elements. Besides in-role performance, the performance beyond the traditional role expectations matter as well. This is where the potential of engagement comes in. Employee engagement might pass through the joint organization of employee representation. Any support structures through unions can contribute to this engagement process. Democratic participation structures seem to be an important element of a modern structure of representation that includes the "low engagement generation" of younger employees, as claimed in the "Brexit" voting. New technologies through new channels of communication and possibly including electronic voting possibilities beyond the like button could be a forward-looking strategy for unions as well.

The extra-role performance builds on the concept of Organ [28] who coined the concept of organizational citizenship behaviors. This well-known concept describes an employee's willingness to put in extra effort beyond the expected own individual performance or expectations. Voluntary activities without direct link to financial compensation are major elements of organizational citizenship behavior and even the willingness to overcome inconvenient situations not only for oneself but also for others in the organization. This concept from the scientific management literature enriched by Whittington and Galpin ([27], pp. 21-22) concludes on the importance of authentic leaders to rely on transparent decision-making and rules. Of course, this claim for transparency links into the trust building and ultimately into employee engagement embedded into organizational citizenship. For all employee and union representatives the time consuming effort to build transparent structures, trust for extra-role performers becomes a crucial issue. Support structures need to comprise up-to-date electronic facilitators. New technologies that a user can manage through smart phones might even become a top priority for unions now and in the next few years.

The evolution of concepts of "Liquid Feedback" or "Liquid Democracy" [29] has been closely followed by political parties and other democratic or representative organizations (e.g. employer organizations in Germany, see for example "Digitale Demokratie 2012"). The rise and fall of the political party using the concept of liquid democracy or liquid feedback as a kind of operating system has 
been issue of much research [30]. The liquid feedback system was originally developed under a MIT open source license in the U.S. The popular on-line encyclopedia Wikipedia states for the definition of liquid feedback: "is free software for political opinion formation and decision making, combining aspects of representative and direct democracy." (Wikipedia, 2016

https://en.wikipedia.org/wiki/LiquidFeedback) and the producing organization (http://www.liquidfeedback.org/) describes the software as: "Liquid Feedback is an open-source software, powering internet platforms for proposition development and decision making". Of course, there exists already a short video explaining the basic intention and features of the system on the video platform "youtube".

The major challenge for employee representation seems to be the joining of the online world and feedback given in spontaneous form with the analog, presence based form of democratic procedures. The technical problems associated with the software have ultimately caused even the closing of the system in the political party in some instances. Nevertheless, advances in voting technologies and basic support for online information and voting systems has the potential to enhance legitimacy as well as democratic principles in organizations based on representative decision-making. However, we need to carefully study and evaluate the new systems in order to really be sure that they improve participation and processes. It appears to be the case that only some elements of the technological innovations are useful for broader use in unions. The current literature on user experiences both from consumer research [31] suggests some lines of arguments that, nevertheless, require additional, detailed research on specific applications for trade unions. Of course, such evaluations have to be undertaken with hands-on users within the union movement.

User experience remains central to any new technology application or support. The recommendations in the "industrial worker" article from 2008 highlights the ease of use and the need to accompany any introduction of new electronic devices in the unions with substantial peer support ([32], p. 4). In more technical or scientific language this statement reads like this: "mobile application designers may consider the situation of these user segments by simplifying the interface of their applications" ([32], p. 234). The basic message remains the same accessible language should be used. For example, even a simple open text field "enter your name" can be subject to interpretation as the use of abbreviations or pseudonyms might be an option, not least to mention foreign language characters common in names.

The liquid democracy systems appear promising with respect to their potential to increase the level of participation both for information and decision purposes. From the assessment and scientific evaluations of the liquid feedback system within the political party "the pirates" in Germany there are mixed signals. Klecha and Hensel [30] point towards the importance of professionalization and, despite the digital presence of the many, the need to empower key persons. This 
provides for the urge to give the organization a human face simultaneously to on-line communication and delegation.

Of a similar kind is the "Loomio" experience. The cooperative social enterprise "Loomio" introduced an online tool for collaborative decision-making. It is used by many people and in more than 20 countries. The areas of application with trade union relevance have been limited so far to an example related to the health and safety field. As for the other technological advances, a more thorough evaluation of the experience remains to be done. The web-based information on the application of the tool at least seems promising (http://blog.loomio.org/2016/07/08/worker-participation-in-health-safety/). The advocate and founder of the (https://www.youtube.com/watch?v=4vCL4I19o9U) technological support software Ben Knight is convinced that the tool can make everyday democracy function more effectively. Of course, we shall follow up on this promise from a union perspective.

Another example of pushing transparency of democratic processes further ahead is the vote counting transparency pioneered by "clearballot"

(https://www.clearballot.com/). The scanning of voting slips and checking the validity of votes plus an additional automated counting constitutes a way to reduce work of voluntary assistance. In addition, it provides a way that results obtained by manual counting be checked easily to confirm results. All these measures increase by means of enhanced transparency the legality and legitimacy of voting procedures. With at least partially some of these procedures in place it should have been possible, for example, to avoid the re-running a financially costly re-election as just occurred at the instance of the Austrian presidential election.

These are some forward-looking solutions to advance basic democratic principles and procedures. However, this paper provides only appetizers rather than thorough evaluations of these tools. In order to avoid that unions are at the risk of being "short-circuited" by new movements the development of an own internal digital agenda is of high importance. Discussing the zero marginal cost society by Rifkin [32] is a necessary starting point. The efforts of the "Arbeiterkammer" [15] to strategically tackle digital change with a broad encompassing approach is a much more detailed compendium of next steps.

\section{Examples of Unions' Adoption of IT Solutions}

The first issue that requires attention is data protection. In order to counter concerns about lack of privacy and use of information by non-authorized persons or institutions each application has to provide information on suitable certification to stick to the best available and most recent standards. Until recently, these standards were largely set by a country well beyond the insufficient but still commonly used recourse to the much criticized and outdated EU Directive 95/46/EC. This Directive is known under the title of the "Safe Harbour agreement". It is now up to all organizations to quickly update their data protection 
information on websites and software used to refer to the new EU-US Privacy Shield as reference.

Most countries have in parallel introduced own regulation that governs e-government as well as e-commerce relationships. A good practice example is the note on the webpage within the Austrian Trade Union Federation (http://www.oegb.at/cms/S06/S06_11/english) and more specifically their newsletter solidarity "Solidarität" (http://www.soli.at/cms/S06/S06_50.9.1) has a link on data protection about the use of their webpage. Additionally, the latter address reflects careful consideration of data protection issues. For example, even the advertiser for address changes in the journal is certified with the Austrian e-government certificate.

E-government initiatives in many European countries by now allow to carry out tasks through electronic access rather than by mail, phone calls or personal visits to government agencies. Already in 2015 the number of electronic submission of tax statements passed 16 million cases in Germany). The certification following ISO 27001 through another government agency seems to work in favor of a trusted connection of transmission of sensitive earnings, income and family or household data. In order to keep a European compatibility some organizations or companies refer back to the European label of e-commerce. The guidelines of the e-government certificates ensure a high standard of data protection and, therefore, provide a sufficiently trustworthy data security check of the system.

Interesting cases from the union movement that have adopted new IT technology are the facebook like application called "unionbook"

(http://www.usunions.com/) with more than 250 subgroups on special topics or member groups. The facebook of union members is developed with use of a software from NING, a California based enterprise http://www.ning.com/. The data protection rules are conform to the U.S. standards and only after the adoption of the European Directive of the Privacy Shield [33] special protection for European data users will be implemented. Currently there is an individual country-specific data protection scheme applied for each European country.

In pursuing a sampling strategy of trade union press across Europe based on a document from the European trade union institute [34] we were able to identify some interesting examples of adoption. The most prevalent cases are the shift over from printed newsletters to electronic formats, mostly in addition to the printed forms. An outstanding example is, in our opinion, the online webinar format of the "Djof" (https://www.djoef.dk), the Danish union of lawyers, economists and social scientist. The access is open to the public and not reserved for members. Access to the world of online information and learning opportunities linked to unions and employee participation could itself be a worthwhile goal. Digital technology facilitates the democratization of access to such information.

The presence of the IG-Metall at the international computer and software fair 
in Hannover "Cebit" (http://www.itk-igmetall.de/cebit2014) features the adoption of new technologies in the organization besides the efforts to recruit members on the fair. The availability of four separate apps is a good practice example. These apps contain information on collective agreement guidelines, labour law and regulations as well as information on apprenticeship and training opportunities. The offer for members to visit the fair free of charge

(https://www.igmetall.de/die-ig-metall-auf-der-cebit-2016-15902.htm) constitutes surely a generous offer for informal learning on the potential of digital technologies as well as critical assessments. Interviews conducted at the occasion of the Cebit revealed that IG-Metall representatives understood as their primary role advising of members in cases of conflict related to digital technology. The major fields currently were data protection and mobbing through electronic media. Limits in the adoption of new online forms of collaboration in the organization consist in the respect of confidentiality.

Limitations of the research so far are the limited scope of positive examples of trade unions adopting new technologies to manage their members, enhance networking among members and delegates as well as decision-making on actions. The current state of this overview is not complete and it is based on official trade union publications. To go further, more in-depth interviews need to be carried out to facilitate a more complete coverage of union actions that are technology enabled or supported. More examples from other non-European countries need careful investigation. Asian countries with more technology-expert persons also within the union movement might be of particular interest.

Another limitation is the unsystematic access to information about the drivers of and barriers to adoption of digital technologies. Of special interest is the age distribution of union membership compared to the users of digital technologies. In order to narrow the suspected gap between the two age distributions should be a promising field of research. Additionally a more precise analysis of each digital technology case by case should allow to be more specific in propositions for new digital tools for the trade union movement.

\section{Conclusions}

Social Media are a digital technology that facilitates networking and organizing for the trade union movement. However, social media are only a part of the full potential of IT-technology to help prepare, mobilize and organize industrial action as well as collective decision-making. Across the full range of the spectrum of what constitutes employee participation from the matrix view of it (compare with Figure 1) to the ladder or hierarchical perspective (compare with Figure 2), all of these variations of the same theme have ample scope to be supported by new digital technologies in a productive, more efficient and more democratic way.

Digital technologies have the potential to take broader grass-roots-based-initiatives into account. They can move direct democracy elements from the level 
of the few to many, if not all (compare with Figure 1). This potential of digital technologies appears to us the way forward to broaden traditional memberships and to facilitate the work of union representatives and the many voluntary initiatives. These tools facilitate the work of the numerous volunteering persons on the shop floor. The aim to be an attractive "good practice" organization for young generations of labour market entrants is additionally boosted with an up-to-date embracing of new digital technologies.

Doodle polls for meeting planning (https://doodle.com/free-poll), Adobe Connect (https://www.adobe.com/products/adobeconnect.html), Cisco WebEx (https://www.webex.com/) for video conferencing to reduce commuting time for meetings and coordination, Skype Calls or joint project canvases

(https://www.projectplace.com/) to mention just a few tools. All these tools are by now common tools in some professional worlds as well as volunteering organizations, NGOs or in leisure activities. We witness the enlargement of the traditional space of office software by many new digital tools. We have been getting used to a lot of software in professional and private areas of our social life. These tools will continue to grow and particularly younger generations of so-called digital natives, but also more and more experienced workers will grow into using these tools. It is more the question of whether we do it as frontrunner or laggard. Do we support our members in these efforts with competent advice and through trade union education institutions or do we leave our members to make their own experiences in this important field?

Unions could support their members in bridging the digital divide through services and peer learning ([35], p. 39). For this to become a more realistic scenario, we have to collect more systematically the best practice from within the trade union movement across countries and not limited to national boundaries. Singular good practice like the French initiative called "T3R1" (https://syndicoop.fr/) short for "terrain", a network of cooperatives supporting union activities in the digital provision of services with ICT-technologies are a promising move in the right direction [2].

The new "privacy shield" [33] allows for more far reaching and effective protection of European citizen's rights. In case of data protection violations, Europeans have now access to affordable dispute resolution mechanisms. Having signaled an infringement of data protection with the company, companies covered under the Privacy Shield provisions "can opt between free of charge Alternative Dispute resolution (ADR) or voluntary submission to the oversight of the EU Data Protection Authorities". The use of social media and other software under U.S. licenses can, therefore, no longer claim sole authority of regulation in this very sensitive field of data protection. Particularly, highly confidential data have a much higher level of protection now as in the case of professional and voluntary network data of people.

With this provision in place, social media, web-based applications for meeting, information exchange and elaborated voting systems are ready to support 
the trade union movement. Incorporating digital technologies more fully with support and learning infrastructure is an additional way to contribute to closing the inequality due to the digital divide.

\section{References}

[1] Dunn, M. and Walker, J. (2016) Union Membership in the United States: Spotlight on Statistics. Bureau of Labor Statistics, Washington DC.

http://www.bls.gov/spotlight/2016/union-membership-in-the-united-states/home.htm

[2] Cadres Infos (2015) T3R1 : un réseau de coopératives numériques au service de l'action syndicale, $\mathrm{nr} 721$. https://syndicoop.fr/

[3] Degryse, C. (2016) Digitalisation of the Economy and Its Impact on Labour Markets. ETUI Working Paper 2016.02. https://doi.org/10.2139/ssrn.2730550

[4] Bijker, W.E., Hughes, T.P. and Pinch, T.J. (2001) The Social Construction of Technological Systems: New Directions in the Sociology and History of Technology. MIT Press, Cambridge, MA, 17-48.

[5] Hyman, R. (2016) The Very Idea of Democracy at Work. Transfer. European Review of Labour and Research, 22, 11-24. https://doi.org/10.1177/1024258915619283

[6] Mückenberger, U. (2016) Citizenship at Work. A Guiding Principle for Social and Trade Union Policy. Transfer: European Review of Labour and Research, 22, 25-44. https://doi.org/10.1177/1024258915619360

[7] Lévesque, C. and Murray, G. (2010) Understanding Union Power: Resources and Capabilities for Renewing Union Capacity. Transfer. European Review of Labour and Research, 16, 333-350. https://doi.org/10.1177/1024258910373867

[8] Holgate, J. (2015) Community Organizing and the Implications for Union Revitalization. ETUI Policy Brief Nr. 4/2015.

[9] Danaj, S. and Sippola, M. (2015) Organising Hyper-Mobile Transnational Construction Workers. ETUI Policy Brief Nr. 11/2015.

[10] Rogers, E.M. (2001) The Digital Divide. Convergence: The International Journal of Research into New Media Technologies, 7, 96-111. https://doi.org/10.1177/135485650100700406

[11] Vitols, S. and Kluge, N. (2011) The Sustainable Company: A New Approach to Corporate Governance. European Trade Union Institute, Brussels.

[12] Gospel, H. (2011) Employee Representation and the Sustainable Company In: Vitols, S. and Kluge, N., Eds., The Sustainable Company: A New Approach to Corporate Governance, 59-74.

[13] European Commission (2016) Europe 2020 Strategy. The Digital Agenda. https://ec.europa.eu/digital-single-market/en/europe-2020-strategy

[14] European Commission (2016) Digital-Scoreboard. https://ec.europa.eu/digital-single-market/en/digital-scoreboard

[15] Arbeiterkammer, (2016) Digital Change-Fair and Just. https://media.arbeiterkammer.at/wien/PDF/studien/digitalerwandel/Visionenpapie r_DigiWa_ENGLISCH.pdf

[16] Veugelers, R. (2016) The European Union's Growing Innovation Divide, Bruegel Policy Contribution.

[17] OECD (2016) Skills Matter. Further Results from the Survey of Adult Skills. 
http://www.oecd.org/skills/piaac/skills-matter-9789264258051-en.htm

[18] Fox, J. and Shotts, K.W. (2009) Delegates or Trustees? A Theory of Political Accountability. The Journal of Politics, 71, 1225-1237. https://doi.org/10.1017/S0022381609990260

[19] Madison, J. (1788) The Senate. The Federalist No. 62. http://www.constitution.org/fed/federa62.htm

[20] Boyne, G.A., James, O., John, P., et al. (2009) Democracy and Government Performance: Holding Incumbents Accountable in English Local Governments. The Journal of Politics, 71, 1273-1284. https://doi.org/10.1017/S0022381609990089

[21] Cullinane, N., Hickland, E., Dundon, T., et al. (2015) Triggering Employee Voice under the European Information and Consultation Directive: A Non-Union Case Study. Economic and Industrial Democracy, 38, 629-655. http://www.egovernment-monitor.de/die-studie/2015.html

[22] Leschke, J. and Vandaele, K. (2015) Explaining Leaving Union Membership by the Degree of Labour Market Attachment: Exploring the Case of Germany. Economic and Industrial Democracy, 1-23. https://doi.org/10.1177/0143831X15603456

[23] Kirton, G. (2015) Anatomy of Women's Participation in Small Professional Unions. Economic and Industrial Democracy. https://doi.org/10.1177/0143831X15606981

[24] Brøgger, B. (2010) An Innovative Approach to Employee Participation in a Norwegian Retail Chain. Economic and Industrial Democracy, 31, 477-495. https://doi.org/10.1177/0143831X09358364

[25] Upchurch, M. and Grassman, R. (2015) Striking with Social Media: The Contested (Online) Terrain of Workplace Conflict. Organization. https://doi.org/10.1177/1350508415598248

[26] Oberfichtner, M. (2016) Works Council Introductions in Germany, Do They Reflect Workers' Voice? Economic and Industrial Democracy.

[27] Whittington, J.L. and Galpin, T.J. (2010) The Engagement Factor: Building a High-Commitment Organization in a Low-Commitment World. Journal of Business Strategy, 31, 14-24. https://doi.org/10.1108/02756661011076282

[28] Organ, D. (1988) Organizational Citizenship Behavior: The Good Soldier Syndrome. Lexington Books, Lexington.

[29] Behrens, et al. (2014) The Principles of Liquid Feedback. Interaktive Demokratie e. V., Berlin.

[30] Klecha, S. and Hensel, A. (2013) Zwischen Digitalem Aufbruch und analogem Absturz: Die Piratenpartei. Opladen, Barbara Budrich.

[31] Hon, L.C., Cui, X. and Na, S. (2016) How Do Different People Evaluate Mobile Applications? A Study on Demographic Characteristics and Utilitarian Mobile Applications. Global Journal of Emerging Trends in e-Business, Marketing and Consumer Psychology, 1, 222-238.

[32] Rifkin, J. (2014) The Zero Marginal Cost Society. St. Martin’s Press, New York.

[33] European Commission (2016) EU-U.S. Privacy Shield: Frequently Asked Questions. http://europa.eu/rapid/press-release_MEMO-16-2462_en.htm

[34] ETUI (2003) A Directory of Trade Union Press in Europe. ETUI, Brussels.

[35] Böker, K.H., Demuth, U., Thannheiser, A. and Werner, N. (2013) Social Media-Soziale Medien? Neue Handlungsfelderfür Interessenvertretungen Edition, Hans Böckler Nr. 281. 